\title{
||||||||||||||||||||||||||||||||||||||||||||||||||||||||||||||||||||||.
}

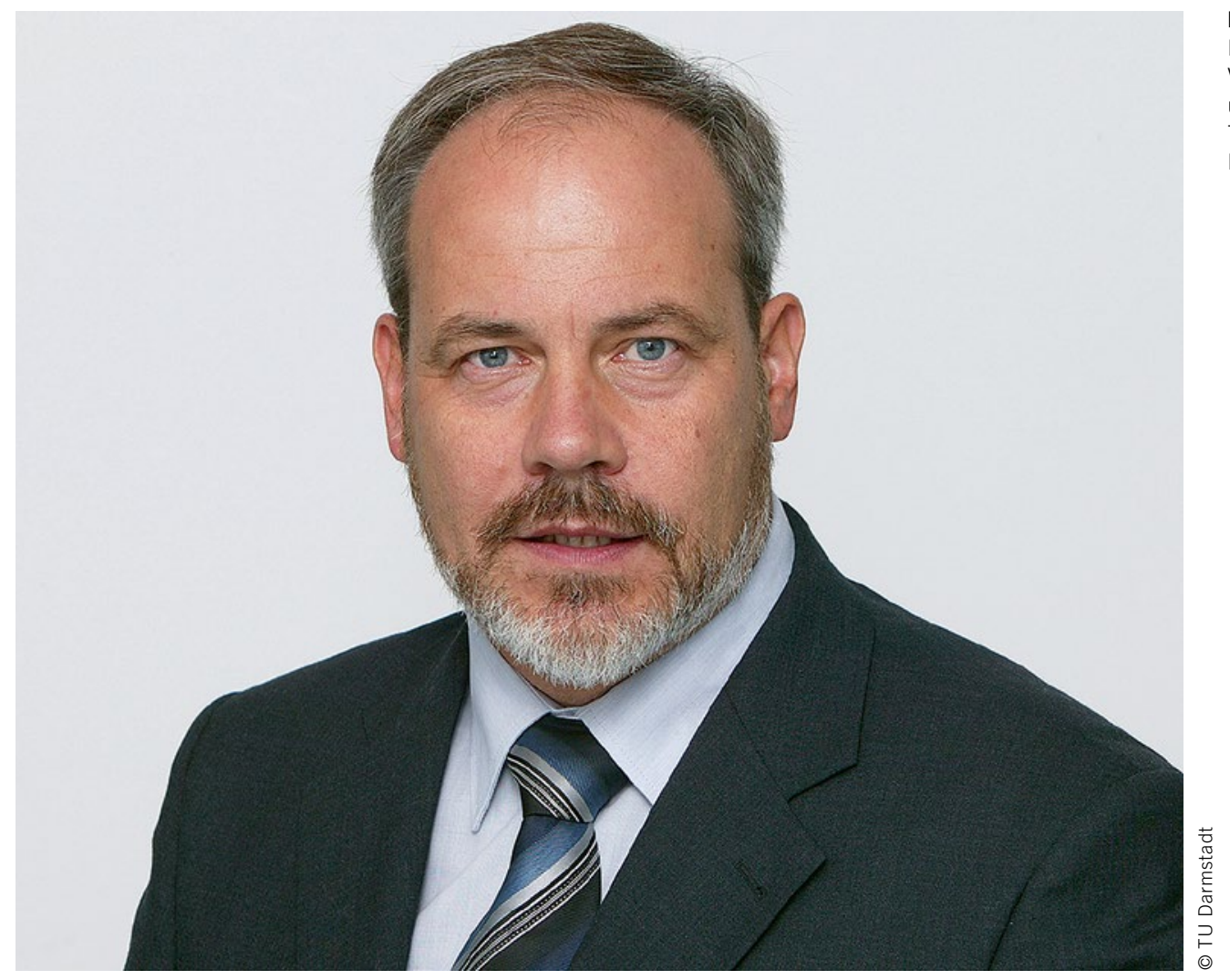

Prof. Dr. Christian Beidl Leiter des Instituts für Verbrennungskraftmaschinen und Fahrzeugantriebe, Technische Universität Darmstadt

\section{Neue Dimensionen}

Digitalisierung ist überall. Und es vergeht kein Tag, an dem nicht über zukünftige Antriebsstrategien berichtet wird. Der Verbrennungsmotor erfindet sich gerade neu, die Elektromobilität steht an der Schwelle, sich im Markt beweisen zu müssen. Der isolierte Blick auf den Fahrzeugantrieb genügt nicht mehr, er ist Teil des Energiesystems geworden und muss seine Funktion in einem digital vernetzten Umfeld erfüllen; die Realfahrteigenschaften sind in Zukunft auch Basis gesetzlicher Bestimmungen.

Die Veränderungsgeschwindigkeit ist förmlich spürbar geworden. Die Kunden wollen aber weiter attraktive und robuste Eigenschaften zu fairen Preisen. Das alles lässt darauf schließen, dass die Produkt- und Variantenvielfalt auf absehbare Zeit nicht abnehmen wird, die Absicherungsprozesse hingegen in ihrer Komplexität zunehmen werden. Die Anforderungen durch die RDE-Gesetzgebung zeigen dies sehr deutlich auf.

In dieser Situation spielt die Entwicklungsmethodik eine entscheidende Rolle und wird den zukünftigen Wettbewerb bestimmen. Dafür sind aber grundlegend neue Ansätze notwendig und es müssen wohl auch einige Knoten durchschlagen werden. Ein Schlüsselbegriff ist die Virtualisierung, die gleich mehrere Aspekte mit sich bringt und sich damit deutlich vom klassischen „Frontloading“ unterscheidet: durchgängige Modellierung vom Entwurf bis zur Serienfreigabe und noch darüber hinaus auf Komponenten- und Systemebene, Co-Simulation der unterschiedlichen funktionalen Eigenschaften, nahtlose Verknüpfung von Simulation und Versuch in allen Phasen des Entwicklungsprozesses, auch unter Einbeziehung von Felddaten. Das erfordert eine deutlich effektivere Nutzung großer Datenmengen und auch eine entsprechende Synchronisierung von Hardware- und Softwareentwicklung. Damit aber noch nicht genug: Das Fahrzeug der Zukunft - wir nennen es Fahrzeug 5.0 - interagiert in hohem Maß mit seinem Umfeld und optimiert sich ständig selbst, sei es nun hinsichtlich Effizienz und Emissionen oder für automatisierte Fahrfunktionen. Dies ermöglicht eine deutlich bessere, nutzungsgerechte Auslegung des Antriebs, setzt jedoch eine strukturierte Konnektivität mit entsprechender Datensicherheit voraus. Damit wird auch diese Funktionalität integraler Bestandteil des Absicherungsprozesses.

$\mathrm{Zu}$ all diesen Herausforderungen gibt es vielversprechende Ansätze und wir dürfen uns auf eine Phase intensiver Weiterentwicklung freuen. Nur eines geht definitiv nicht: abwarten. 